\title{
Investigation and Research on Mental Health Problems of Poor College Students in Old Revolutionary Areas
}

\author{
Xiaoqin Qi, Linli Kong \\ College Student Mental Health and Educational Center, Huanggang Normal University, Huanggang, China \\ Email: yangbp@hgnu.edu.cn
}

How to cite this paper: Qi, X. Q., \& Kong, L. L. (2021). Investigation and Research on Mental Health Problems of Poor College Students in Old Revolutionary Areas. Open Journal of Social Sciences, 9, 581-589. https://doi.org/10.4236/jss.2021.95033

Received: April 13, 2021

Accepted: May 22, 2021

Published: May 25, 2021

\begin{abstract}
In August 2015, General Secretary Xi Jinping stressed at the National Hygiene and Health Conference that "we should increase basic research on mental health issues, do a good job in popularizing knowledge about mental health and diseases, and standardize the development of mental health services such as psychological treatment, counseling and so on". Lead "little bees" team to visit poor students and collect their information, giving follow-up and one-on-one support to them four years in a row, adopting relevant research method to investigate mental health problem of poor college students in the interaction of parent-school cooperative education, employment, interpersonal relationship, academic and career planning. The result shows that it is most critical and important to give full play to the leading role of impoverished college students' own self-education.
\end{abstract}

\section{Keywords}

Poor College Students, Mentality, Mental Health, Little Bees Team

\section{Introduction}

In recent years, the rights and opportunities of poor college students to receive higher education have been guaranteed to a certain extent under the diversified and mixed aid methods of state award, student loan and grant, exemption, subsidy. However, with the changes of economic, social and ethical values, the mental health problems of poor college students due to material poverty have not been effectively solved in the short term (Li \& Yang, 2019).

Huanggang, the old revolutionary base area, is economically backward. Huanggang Normal University as a local college, many students of the university 
come from the local rural areas in Huanggang, with impoverished backgrounds. Maslow's hierarchy of needs, an American social psychologist, rises in turn. "1) physiological needs, 2) safety needs, 3) social needs, 4) esteem needs, and 5) self-actualization needs". In his opinion, physiological needs are the most basic and the most intense among all kinds of human needs. Due to family economic conditions (Ran, 2020), poor college students often fail to meet even the most basic survival needs, and become self-abased, solitary, aloof, and anxious (Chen, 2020). Inferiority complex is the primary problem of college students in psychological characteristics, with economic poverty, many college students are in a very fragile condition, and they get few emotional supports, so many poor students' psychological pressure is too high, ultimately they drop out of the school or even commit suicide (Fan, 2020), which is not conform to the reality of "people-oriented" society.

In order to have a better understanding on the poor students' family conditions, learning situation and psychological state, and offer them help in time, interview survey is carried out specially to get further understanding of the poor students' family conditions and psychological state, and put forward the corresponding solutions and measures. "little bee" team headquarters in the student affairs department of Huanggang normal university, "bee" are the officer representatives who have visited thousands of the poor family. During the holidays (winter or summer vacation), teachers visited special poor family, on the basis of visiting, they have been collected poor students' information from students' first year in the college, and established archives for poor students, carried out "one to one" support (each a poor student have an assigned teacher or student who is responsible for the contact, dynamic track on students (study, life, psychology, etc.) until these students get out of poverty or graduate. assistant resources, such as: school financial aid, psychological counseling, work-study jobs, etc., which help students successfully complete their college studies, and effectively solve the practical problems of poor students. Meanwhile, by using professional psychological scale SCL-90, the mental health status of poor and non-poor college students in Huanggang Normal University was investigated to compare the differences between those two groups. By means of self-compiled questionnaire and individual case interview, the root causes of mental health problems of poor college students are deeply understood. Through the conclusion of the empirical study, the theoretical and practical guidance is provided to strengthen the ideological and political education, mental health education of poor college students, so as to effectively put forward the strategies and methods for the ideological and political education and mental health education of poor college students in $\mathrm{Hu}$ anggang Normal University.

\section{Research Objects and Methods}

\subsection{Research Objects}

Respondent 1: Students of Huanggang Normal University were selected by 
stratified sampling. 500 questionnaires were distributed, 480 were recovered, and the recovery rate was $96 \%$. Among them, 450 were valid, with an effective rate of $94 \% .115$ people in the survey, the number of freshmen and sophomore students, 126 junior students in 110 people, senior students in 99 people, among them, the boys in 290, the number of girls, 160 liberal arts students 178 people, 272 people in science and engineering students, poor students 121 people, of which 42 people in cities, rural areas, 79 people, the poor students, 329, including 270 people in the city, 59 people in the countryside.

Respondent 2: 10 college students, 5 male students and 5 female students from Huanggang Normal University were selected.

\subsection{Research Tools}

\subsubsection{Symptom Checklist 90 (SCL-90)}

Clinical Checklist 90 (SCL-90) (Ren, 2009), also known as self-reporting Inventory, sometimes called Hopkin's Symptom Inventory (HSCL, compiled earlier than SCL-90 by the same author, HCSL was first compiled in 1954) compiled in 1975 and written by L. R. Derogatis. This scale has a total of 90 items, including a wide range of psychiatric symptoms, including feelings, emotions, thinking, consciousness, behavior, life habits, interpersonal relationships, eating and sleeping, etc., and uses 10 factors to reflect the psychological symptoms of 10 aspects.

\subsubsection{Self-Made Questionnaire}

According to the existing research, the questionnaire on common mental health of poor college students was compiled by ourselves. It was an open questionnaire with 9 questions, mainly to understand the conditions of common psychological distress, psychological desire for help and basic social support of poor college students. Typical questions, such as: When you have a problem, especially a psychological problem, how do you usually solve? In general, who do you turn to for help?

\subsubsection{Case Interview}

Through semi-structured interviews, the author has a deep understanding of the mental health, social support, willingness to seek help and self-acceptance of poor college students.

\subsection{Test Procedures}

For the first two questionnaires, a collective test was carried out. Questionnaires were distributed on campus and then collected. The case interview was carried out in the way of face-to-face communication.

\subsection{Statistical Processing of Data}

SPSS11.5 was used for statistical processing and analysis. 


\section{Investigation Results and Analysis of Psychological Problems of Poor College Students}

\subsection{Comparison of Mental Health Status between Poor and Non-Poor College Students}

Independent sample $\mathrm{T}$-test is used to test the difference between poor and non-poor college students in SCL-90 scores (Xia \& Ai, 2018), and the results are shown in Table 1. The results show that there are significant differences in somatization, obsessive-compulsive symptoms, interpersonal sensitivity, depression, anxiety, psychosis and SCL-90 total scores, and the scores of poor college students are significantly higher than those of non-poor college students.

\subsection{Psychological Problems Detection Rate of Poor College Students in SCL-90}

According to the scoring rules of the SCL-90 scale, if the factor reaches 2, the item is considered to have symptoms; if the factor reaches 3 , the problem severity of the item is above medium, which may require further diagnosis and treatment (Liang, 2002). As shown in Table 2, almost every factor was detected by poor college students, among which the highest detection rate was anxiety symptoms, followed by obsessive symptoms.

Table 1. Differences in seizure of the poor students and poor students in the SCL-90.

\begin{tabular}{cccccc}
\hline \multirow{2}{*}{ factor } & \multicolumn{2}{c}{ Poverty group } & \multicolumn{2}{c}{ poor group } & \multirow{2}{*}{$\mathrm{T}$} \\
\cline { 2 - 5 } & average & standard deviation & average & standard deviation & \\
\hline somatization & 1.60 & 0.17 & 1.50 & 0.16 & $2.75^{\star *}$ \\
Forced symptoms & 1.59 & 0.13 & 1.51 & 0.17 & $3.32^{\star *}$ \\
Interpersonal sensitivity & 1.89 & 0.12 & 1.42 & 0.12 & $3.23^{\star *}$ \\
depression & 1.79 & 0.14 & 1.45 & 0.17 & $3.77^{\star *}$ \\
anxiety & 1.72 & 0.15 & 1.54 & 0.11 & $3.24^{* *}$ \\
psychotic & 1.69 & 0.17 & 1.43 & 0.11 & $2.75^{\star *}$ \\
\hline
\end{tabular}

${ }^{* *} P<0.01$.

Table 2. Detection rate of psychological problems of poor students in the SCL-90.

\begin{tabular}{ccccc}
\hline factor & $\mathbf{2}$ (number) & $\begin{array}{c}\text { Detection rate } \\
\text { (\%) }\end{array}$ & $\mathbf{2 3}$ (number) & $\begin{array}{c}\text { Detection rate } \\
\text { (\%) }\end{array}$ \\
\hline somatization & 17 & 14 & 10 & 12 \\
Forced symptoms & 39 & 32 & 12 & 10 \\
Interpersonal sensitivity & 23 & 19 & 12 & 10 \\
depression & 23 & 19 & 11 & 11 \\
anxiety & 89 & 74 & 48 & 40 \\
psychotic & 15 & 12 & 6 & 5 \\
\hline
\end{tabular}




\subsection{Comparison of Mental Health Status and Norms of Poor College students}

The mental health level of poor college students in this sample is compared with the domestic norm, and the sample $\mathrm{T}$ test is carried out. As it can be seen from Table 3 that the factors and total scores of poor college students in SCL-90 are significantly higher than the domestic norm and reach a significant level (Gong, 2003).

\subsection{Results of Self-Compiled Questionnaire Survey}

Nine open-ended questions were designed to investigate the responses and responses of poor and non-poor college students to these questions.

Question 1: what do you think is the most difficult thing in your college life (Yang, 2008)?

As for the answer to this question, the main questions include the following aspects: The first is the concern about employment. Students from rural areas and poor families, in particular, generally expressed concern about the issue. This is also the reality of today's society. With the increasing employment pressure of college students, employment has become the focus of all common concern. Especially in the senior students, the performance is particularly prominent, because they will directly face the employment problem, is inevitable. The second problem is interpersonal problems. Among college students, there are not a few who are troubled by interpersonal relationship. This is the first time for many students to leave their hometown, and living in a collective dormitory is uncomfortable for many of them. Lack of social skills and inability to communicate with others is a serious problem. At the same time, college life, unlike high school as there is a heavy workload, the students are in the classroom every day, so mutual communication and exchange is more convenient. The third is learning difficulties. This point is mainly reflected in the expression of science and engineering students. Because in university, a lot of learning content and process are mastered by oneself, and students need to play a leading role in the learning process when there is little supervision from teachers. In addition, the light

Table 3. Poor mental health of students and the norm.

\begin{tabular}{cccccc}
\hline & \multicolumn{2}{c}{ poor students $(\mathrm{N}=121)$} & national norm $(\mathrm{N}=1388)$ & T \\
\cline { 2 - 4 } factor & average & $\begin{array}{r}\text { standard } \\
\text { deviation }\end{array}$ & average & $\begin{array}{c}\text { standard } \\
\text { deviation }\end{array}$ & \\
\hline somatization & 1.60 & 0.17 & 1.37 & 0.48 & $3.91^{* *}$ \\
Forced symptoms & 1.59 & 0.13 & 1.62 & 0.58 & $9.27^{\star *}$ \\
Interpersonal sensitivity & 1.89 & 0.12 & 1.65 & 0.61 & $3.99^{* *}$ \\
depression & 1.79 & 0.14 & 1.50 & 0.59 & $6.35^{* *}$ \\
anxiety & 1.72 & 0.15 & 1.39 & 0.43 & $7.11^{* *}$ \\
psychotic & 1.69 & 0.17 & 1.29 & 0.42 & $9.11^{* *}$ \\
\hline
\end{tabular}

${ }^{*} P<0.01$ 
workload makes many students focus on recreational activities and fail to complete their academic tasks in time. Especially with the popularity of the Internet and computers, more and more college students drown in the Internet, and meet a lot of difficulties in their studies, or even cannot complete their studies anddrop out of school, which brought serious harm to the family and society. Fourth, career planning and development. Today's society is a pluralistic era, filled with a variety of values. At the same time, college students are also faced with a variety of choices. In their future to become a what kind of person, what kind of career and so on these questions, is often discussed by college students. In this question, there is no obvious difference between poor and non-poor college students.

Question 2: when you are in a bad mood, do you seek help from others?

In response to this question, 80 percent of college students said they would like to ask others for help, especially when they are sad. But there are also some people, especially poor college students, who do not seek help from others, but hide it or try their best to solve the problem alone.

Question 3: when you are in trouble, especially when you are in psychological distress, what is your preferred solution (Kong \& Zhang, 2005)?

For the answer to this question, there are mainly the following aspects: first, to talk to friends; second, talk to your parents. Third, talk to the teacher; fourth, go to the Internet or smoke, drink and exercise to vent; fifth, keep a journal.

Question 4: generally speaking, who do you turn to for help?

For the answer to this question, the people who ask for help most are their family members and close friends, and there is no difference between poor students and non-poor students on this point.

Question 5: when you encounter psychological problems, are you willing to turn to the psychological counseling center for help (Wang, Shi, \& Wang, 2008)?

In response to this question, the majority of people said no, only a few people said they would like to go to the counseling center for help.

Question 6: to what extent can you usually get psychological support from your parents?

For the answer to this question, non-poor college students are obviously more affirmative than poor students, non-poor college students said that it is easy to get psychological support from their parents.

Question 7: to what extent do you usually get psychological support from your teachers?

There was no clear distinction between poor and non-poor students in the answers to this question, both of them said they received less support from school teachers.

Question 8: to what extent can you usually get psychological support from your classmates?

For the answer to this question, there is no obvious difference between poor students and non-poor students, both of them indicated that they received more 
support from their schoolmates.

Question 9: Overall, are you satisfied with your mental health (Sun, 2011)?

In response to this question, most of the poor students were dissatisfied with their mental health, while most of the non-poor students were satisfied with their mental health.

\subsection{Case Study Results}

A semi-structured interview was conducted with 10 poor college students (Guo $\&$ Chen, 2011) to deeply understand their thoughts and psychological states. The specific results are as follows:

Question 1: what aspects of your college life do you think will be affected by financial reasons?

For this question, poor college students believe that economic reasons will affect their personal life in the following aspects: First, they need a lot of financial support to attend skills training, such as English training, driving test, postgraduate entrance examination, civil service examination and so on. Secondly, the individual nutritional status is improved. Some poor college students live a very tight life indeed, the school's various aspects of the subsidy is limited. So they have to spend less on food, then malnutrition exists. Third, employment intention. In terms of employment choice, students from poor families mostly choose those remote areas or grass-roots units, because the consumption level in big cities is relatively high, and for poor college students who are not well-off, they will face greater pressure of survival. Fourth, socialize. As the saying goes, college campus is also a small social circle. The interpersonal relationship between the students' need to interact with each other, eat together, entertainment together. If a friend's birthday will buy gifts, please have a meal and so on. However, due to financial constraints, poor college students refuse or avoid these activities, which have a certain negative impact on their social relations, leading to long-term isolation and a certain sense of inferiority. In these aspects, poor college students are obviously constrained by economic conditions.

Question 2: do you think people around you have certain prejudices against you? If so, how did you handle it?

For this question, some poor students think it exists, while others think it doesn't. This suggests that different people have different social perceptions of the problem. Those who think "there" are poor students who feel that their wealthier classmates sometimes look down on them and feel they are often pitied. Having a better meal, buying nicer clothes, etc., seems always supervised. When dealing with these biases, they often avoid these. Those who think there is no bias feel family backward economic is not a big thing. They will get the appreciation from others as long as they have self-reliance, exceed others in other aspects, do better than others.

Question 3: Are you satisfied with your current situation in life?

For this question, most of the poor students said they were not satisfied with 
their living conditions. It is mainly reflected in the following aspects: First, they need to further develop their studies to make themselves more outstanding; Secondly, psychologically, they need to further overcome those inferiority, throw away the burden, and live in a more positive life. Thirdly, they need some opportunities to exercise their personal ability. Only in this way can they achieve better development and get the opportunity to stand out in the future job hunting.

Question 4: do you feel that society, including the school, has given you enough help or support?

For this question, most students believe that society and school provide them with great support, especially financial support, which enables them to successfully complete their studies. However, social and school neglect psychological care and support. In addition to financial assistance, they also need the psychological support of achievement.

Question 5: what do you think of asking others for help? Includes financial, psychological and other aspects of help.

For this question, most of the poor students think that they have no choice but to ask others for help, especially for financial help. They want help from others, but not handouts. But they don't complain as much when others can't help.

Question 6: how do you view yourself as a poor student?

For this question, most people think that they cannot decide their own birth, only to have a good acceptance of their own reality, can they have a clearer understanding of themselves. Difficulties are not terrible, they will get the respect of others, and their later lives will be better and better as long as they persevere in self-improvement.

\section{Analysis on the Problems and Causes of the Mental Health of Poor College Students}

Through the above quantitative and qualitative research results, it is not difficult to find that the main problems existing in the mental health of poor college students are as follows (Chen, Li, Huang, \& Guo, 2020). First, the interpersonal relationship is self-closed, inferiority and self-esteem coexist; second, widespread depression; third, serious anxiety, material vanity and ideological dependence. The main reason why is the impoverished family background and high economic pressure; from the results of research and investigation, economic reasons may be one of the main reasons for the mental health problems of poor college students; secondly, the bad culture of the society has brought psychological troubles to the poor college students. Third, employment pressure, conflict between dream and reality. March, April and May of each year are the peak of the outbreak of psychological problems for graduating students. During this period, it is common for college students to commit suicide and self-harm. The main reason is employment. Fourth, obvious personality difference between individual, lack of correct self-cognition. 


\section{Conclusion}

Colleges and universities should strengthen the financial aid to poor college students and establish an all-round and diversified financial aid system. It's necessary to create a harmonious family atmosphere, stimulate poor college students' own potential and it is most critical and important to give full play to the leading role of impoverished college students' own self-education.

\section{Conflicts of Interest}

The authors declare no conflicts of interest regarding the publication of this paper.

\section{References}

Chen, M. Y., Li, K., Huang, L., \& Guo, Y. Y. (2020). The Relationship between Personal Goals and Subjective Well-Being of Poor College Students. Psychological Exploration, 40, 372-376.

Chen, T. (2020). Survey on College Students' Cognition of School Mental Health Education Services. Heilongjiang Science, 11, 146-147.

Fan, Y. Q. (2020). The Influence of College Students' Perception of Social Support on Mental Health. Higher Education Forum, No. 3, 87-90.

Gong, Y. X. (2003). Psychological Assessment (pp. 306-307). Beijing: Higher Education Press.

Guo, M., \& Chen, B. J. (2011). Research on the Difference of Mental Health Level and Personality between Poor and Non-Poor College Students. Chinese Journal of Health Psychology, 19, 1365-1366.

Kong, D. S., \& Zhang, J. (2005). Cluster Analysis of Personality Types of Poor College Students. Chinese Journal of Mental Health, 19, 727-740.

Li, P. Z., \& Yang, Z. F. (2019). Thinking of Using Big Data to Subsidize Poor Students in Colleges and Universities. Journal of Shenyang Agricultural University (Social Science Edition), 21, 91-94.

Liang, B. Y. (2002). Encyclopedia of Mental Health and Psychological Counseling (pp. 186-188). Tianjin: Nankai University Press.

Ran, Y. Q. (2020). A Study on the Relationship between Social Support, Self-Esteem and Mental Health of Impoverished College Students. Higher Education Research and Practice, 39, 74-79.

Ren, J. (2009). Analysis on the Status of College Students' Mental Health and Reflection on the Self-Rating Symptoms Scale (SCL-90). Chinese Journal of Health Psychology, No. 17, 158-160.

Sun, C. Y. (2011). The Relationship between Personality Characteristics and Mental Health of Poor College Students. Sichuan Mental Health Guard, 24, 73-76.

Wang, P., Shi, X. Q., \& Wang, H. (2008). Research on Personality and Well-Being of Poor College Students in Xi'an. Advances in Modern Biomedical Science, 8, 539-541.

Xia, Y. D., \& Ai, S. (2018). Investigation Results and Analysis of Mental Health of College Students in Xinjiang. Journal of Chifeng University, 34, 29-31.

Yang, F. (2008). Discussion on the Definition of Psychology of Poor College Students. Modern Preventive Medicine, 35, 112-113. 